\title{
CT characteristics of non-small cell lung cancer with epidermal growth factor receptor mutation: a systematic review and meta-analysis
}

Zenghui Cheng ${ }^{1,2 \dagger}$, Fei Shan ${ }^{1 \dagger}$, Yuesong Yang ${ }^{3}$, Yuxin Shi ${ }^{1}$ and Zhiyong Zhang ${ }^{1 *}$

\begin{abstract}
Background: To systematically investigate the relationship between CT morphological features and the presence of epidermal growth factor receptor (EGFR) mutations in non-small cell lung cancer (NSCLC).

Methods: All studies about the CT morphological features of NSCLC with EGFR mutations published between January 1, 2000 and March 15, 2015 were searched in the PubMed and EMBASE databases. Qualified studies were selected according to inclusion criteria. The frequency of EGFR mutations and CT features of ground-glass opacity (GGO) content, tumor size, cavitation, air-bronchogram, lobulation, and spiculation were extracted. The relationship between EGFR mutations and each of these CT features was tested based upon the weighted mean difference or inverse variance in the form of an odds ratio at a 95\% confidence interval using Forest Plots. The publication bias was examined using Egger's test.

Results: A total of 13 studies, consisting of 2146 NSCLC patients, were included, and 51.12\% (1097/2146) of patients had EGFR mutations. The EGFR mutations were present in NSCLC with part-solid GGO in contrast to nonsolid GGO $(\mathrm{OR}=0.49,95 \% \mathrm{Cl}=0.25-0.96, P=0.04)$. Other $\mathrm{CT}$ features such as tumor size, cavitation, air-bronchogram, lobulation and spiculation did not demonstrate statistically significant correlation with EGFR mutations individually ( $P=0.91 ; 0.67 ; 0.12 ; 0.45$; and 0.36 , respectively). No publication bias among the selected studies was noted in this meta-analysis (Egger's tests, $P>0.05$ for all).

Conclusion: This meta-analysis demonstrated that NSCLC with CT morphological features of part-solid GGO tended to be EGFR mutated, which might provide an important clue for the correct selection of patients treated with molecular targeted therapies.
\end{abstract}

Keywords: Computed tomography, EGFR, Non-small cell lung cancer

\section{Background}

Lung cancer is the leading cause of cancer-related deaths globally, with an estimated 1,589,900 deaths in 2012 [1]. In the USA, over 220,000 patients with lung cancers were diagnosed in 2015, and the 5-year overall survival was only $18 \%$ [2]. In China, approximately 733,300 patients with lung cancers were diagnosed and 610,200 of them died in

\footnotetext{
* Correspondence: zhangzyfd@hotmail.com

${ }^{\dagger}$ Equal contributors

${ }^{1}$ Department of Radiology, Shanghai Public Health Clinical Center, Fudan University, NO.2901 Caolang Road, Jinshan, Shanghai 201508, China Full list of author information is available at the end of the article
}

2015; the number of deaths would be anticipated to be more than one million by 2025 [3, 4]. Most patients with lung cancer are diagnosed at advanced stages and are not eligible for curative surgery due to the lack of early specific signs and symptoms; hence, the prognoses for these patients are usually poor [5-7].

In recent years, the molecular targets of lung cancer, especially for the main histological type non-small cell lung cancer (NSCLC), have been investigated, including epidermal growth factor receptor $(E G F R)$, Kirsten rat sarcoma viral oncogene homolog (KRAS), anaplastic lymphoma kinase $(A L K)$, human epidermal growth 
factor receptor 2 (HER2), etc. Targeted therapy has shown promising benefits for patients who inherited mutations in these genes [8-13]. EGFR, one of these molecular targets with a high frequency of mutation, is a transmembrane receptor tyrosine kinase involved in the signaling pathways regulating cell proliferation, apoptosis, angiogenesis, and invasion [14, 15]. The most common EGFR mutations have been shown to be found in adenocarcinoma in female non-smoker of East Asian ethnicity $[8,9]$, and the mutation rate is reported to be $27-56 \%$ in this population compared with $8-10 \%$ worldwide $[9,16]$. Patients with EGFR mutations demonstrated a high response rate of approximately $70 \%$ to EGFR tyrosine kinase inhibitor (EGFR-TKI) therapy. The progression-free survival (PFS) has been reported to reach 9 to 13 months when EGFR-TKIs are administered as the first-line therapy [17-19]. Two types of method for detecting EGFR mutations are currently available: "screening" assays that detect overall mutations, such as Next Generation Sequencing (NGS) and Sanger Sequencing, and "specific" methods that detect specific known mutations using different approaches, such as Roche's EGFR Mutation Test and Life Technologies' SNaPShot $[20,21]$. However, both methods are costly and not feasible in every lung cancer clinic. CT is a routinely used and relatively cost-effective modality in the diagnosis of lung cancer that presents various imaging features, some of which have been reported to relate with certain histopathological types [22], while these types have been identified to correlate with EGFR mutations [23]. Therefore, we hypothesized that specific CT features of NSCLC were associated with EGFR mutations. In this study, we systematically searched the current medical literature and comprehensively examined the relationship between $\mathrm{CT}$ features and the presence of EGFR mutations in NSCLC patients.

\section{Methods}

This meta-analysis was carried out in accordance to the Preferred Reporting Items for Systematic Reviews and Meta-analyses (PRISMA) statement (Additional file 1. Checklist S1) [24]. The primary procedures were as follows:

\section{Search strategy}

We searched PubMed and EMBASE (Excerpta

Medica database) for all articles about

radiogenomics of NSCLC with EGFR mutation published between January 1, 2000 and March 15, 2015. The medical subject terms and key words used for search were "epidermal growth factor receptor", "EGFR", "lung cancer", "lung carcinoma", "CT", and "imaging" in the Boolean expression: ((epidermal growth factor receptor) OR EGFR) AND ((lung cancer) OR (lung carcinoma)) AND ((CT) OR (imaging)) without language restrictions. Related articles, including those from the references, were also searched.

2. Inclusion/exclusion criteria

Qualified studies were included if they satisfied the following criteria: (1) NSCLC was diagnosed based upon either pathological or cytological results; (2) EGFR mutations were determined by fluorescence in situ hybridization (FISH), immunohistochemistry (IHC), polymerase chain reaction (PCR), or any combination of the above-mentioned methods; (3) CT features of tumors were studied before the determination of EGFR mutation or afterwards in a blinded manner; (4) the association between EGFR mutation status and CT features was investigated; and (5) studies were available with full text articles. The studies were excluded if (1) there was duplicate data or insufficient data; and (2) the articles were abstracts, comments, narrative reviews, or editorials without full-text available.

3. Data extraction

The following information was independently extracted from all eligible articles by two investigators (Cheng Z.H. and Shan F.): first author's name, year of publication, country of origin, number of enrolled patients, frequency of the EGFR gene mutation, detection method, histologic type, and CT features, which included proportion of ground-glass opacity (GGO), tumor size, cavitation, airbronchogram, lobulation, and spiculation. GGO was defined as hazy intensity with visible brochovascular markings in the lung window setting [25]. The proportion of GGO was calculated according to the ratio of the maximum length of GGO to that of total tumor in the largest cross section and classified as follows: (1) solid tumor: $\mathrm{GGO}=0 \%$; (2) part-solid GGO: $0 \%<\mathrm{GGO}<50 \%$, and $50 \% \leq \mathrm{GGO}<100 \%$; (3) non-solid GGO $=100 \%$ [26-29]. Tumor size was measured in the largest cross section by averaging the length and width, and in the largest tumor if multiple tumors were present [26]. Cavitation was defined as airspace within the tumor at the time of diagnosis and prior to biopsy or treatment [30]. Airbronchogram was defined as air-filled small foci or branches within the solid part of tumor [31]. Lobulation was defined as the shallow wavy contour of a tumor's surface with exception of the portion adjacent to pleura [32]. Spiculation was defined as sharp linear projections from the tumor [31]. All the above features were analyzed for each tumor prior to treatment. Any discrepancies between the independent extractions of data were resolved by a mutual review of the original articles for a consensus agreement. 
4. Statistical analysis

All statistical analyses were performed using the Review Manager (RevMan, version 5.3.5) and STATA (version 12.0). All statistical tests were twosided, and the significance level was set at 0.05 .

The association between the CT features and EGFR mutations of NSCLC was assessed based upon the weighted mean difference (WMD) or inverse variance (IV) in the form of odds ratio (OR) [33] at a 95\% confidence interval (95\% CI). Specifically, (1) the association between GGO content (containing GGO or not; non-solid, part-solid or solid; proportion of GGO) and EGFR mutation (some subtypes when available were also included) was tested by WMD for overall effect. (2) Association between tumor size and EGFR mutation was tested by IV for overall effect. (3) Association between tumor cavitation, air-bronchogram, lobulation, spiculation and EGFR mutation was tested by WMD for overall effect.

Heterogeneity was examined by the Chi-square based $\mathrm{Q}$ test. Inconsistency index $\left(\mathrm{I}^{2}\right)$ ranging from 0 to $100 \%$ was utilized to define the inter-trial variability due to heterogeneity rather than to sampling error within the study [34]. A random-effects model based on the Der Simonian and Laird method was adopted if $\mathrm{I}^{2}$ was above $50 \%$, which indicated the presence of a significant heterogeneity; otherwise, a fixed-effect model based on the Mantel-Haenszel method was used if $\mathrm{I}^{2}$ was under $50 \%$.

The publication bias was examined using Funnel plots and Egger's tests. Deviation from the funnel-shaped distribution of eligible studies may indicate the presence of publication bias.

\section{Results \\ Qualified studies}

A total of 2146 patients with NSCLC from 13 qualified articles were included [26-31, 35-41], of whom 1097 patients $(51.12 \%)$ had EGFR mutations. Most studies $(11 / 13)$ were from Asia, including Korea (3), Japan (5), and China (3); the other two studies were conducted in the U.S.A. The EGFR detection techniques included PCR (8 studies), FISH (1 study), IHC (2 studies), PCR and FISH (1 study), PCR and IHC (1 study). The flow diagram of the selection process of the eligible studies is shown in Fig. 1.

Table 1 summarizes the basic characteristics of all qualified articles. The rate of detection of EGFR mutations ranged from 23.83 to $73.91 \%$ based on 13 qualified articles, and the average incidence was $49.00 \%$ in 2146 patients with NSCLC.

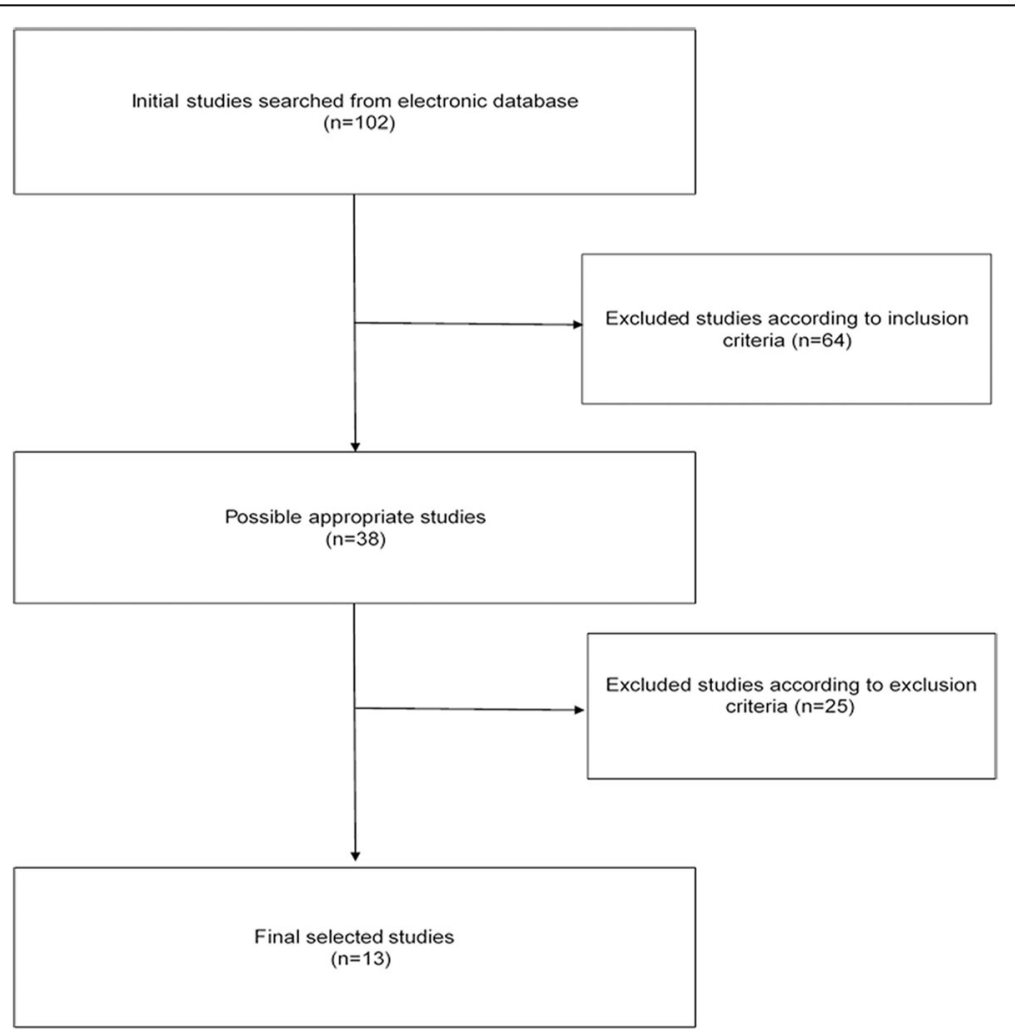

Fig. 1 Flow diagram of the study selection process 
Table 1 Summary of qualified studies

\begin{tabular}{|c|c|c|c|c|c|c|}
\hline Study & Year & Source of Patient & Stage & No & Frequency & Method \\
\hline Lee $Y$, et al. & 2013 & Korea & I & 214 & $23.83 \%(51 / 214)$ & $\mathrm{IHC}$ \\
\hline Lee $\mathrm{HJ}$, et al. & 2013 & Korea & $|-|||$ & 153 & $54.25 \%(83 / 153)$ & PCR, FISH \\
\hline Park EA, et al. & 2009 & Korea & I-IV & 132 & $40.15 \%(53 / 132)$ & $\mathrm{FISH}$ \\
\hline Glynn C, et al. & 2010 & U.S.A & UN & 64 & $32.81 \%(21 / 64)$ & PCR \\
\hline Aoki T, et al. & 2012 & Japan & UN & 25 & $40.00 \%(10 / 25)$ & PCR, IHC \\
\hline Yano M, et al. & 2006 & Japan & $|-|||$ & 80 & $47.50 \%(38 / 80)$ & PCR \\
\hline Yoshida Y, et al. & 2007 & Japan & I & 23 & $73.91 \%(17 / 23)$ & PCR \\
\hline Hsu KH, et al. & 2011 & Taiwan & I & 162 & $64.20 \%(104 / 162)$ & PCR \\
\hline Sugano $M$, et al. & 2011 & Japan & $|-|||$ & 136 & $41.18 \%(56 / 136)$ & PCR \\
\hline Onn A, et al. & 2005 & U.S.A & I & 72 & $66.67 \%(48 / 72)$ & $\mathrm{IHC}$ \\
\hline Usuda K, et al. & 2014 & Japan & I-IV & 148 & $39.19 \%(58 / 148)$ & $P C R$ \\
\hline Yang $Y$, et al. & 2015 & China & 0-IV & 788 & $60.91 \%(480 / 788)$ & PCR \\
\hline Hsu JS, et al. & 2014 & Taiwan & III-IV & 149 & $52.35 \%(78 / 149)$ & PCR \\
\hline
\end{tabular}

Notes: UN unknown, IHC immunohistochemistry, $P C R$ polymerase chain reaction, FISH fluorescent in situ hybridization

\section{GGO and EGFR mutations}

Tumors with or without GGO and EGFR mutation

Eight studies were available for investigation of the relationship between tumors with and without GGO and EGFR mutation. Out of a total of 505 tumors with GGOs and 1041 solid tumors (tumors without GGO), EGFR mutation was detected positively in $56.24 \%$ $(284 / 505)$ and $52.45 \%(546 / 1041)$ of cases, respectively. Figure $2 \mathrm{a}$ summarizes the findings. A randomeffects model was utilized for the meta-analysis due to significant heterogeneity $\left(\mathrm{I}^{2}=78 \%, \mathrm{P}<0.0001\right)$. No statistically significant difference was found between tumors with and without GGO and EGFR mutation in patients with NSCLC (pooled $\mathrm{OR}=1.55,95 \% \mathrm{CI}=$ $0.88-2.73, P=0.13)$.

\section{Tumors with or without GGO and EGFR mutation subtypes}

Three studies were available for investigation of the relationship between tumors with and without GGO and the EGFR mutation subtypes, which included a total of 252 tumors with GGOs and 721 solid tumors. EGFR exon 21 mutation (L858R) was detected in 31.35\% (79/ 252) and 30.93\% (223/721) of cases, while EGFR exon 19 deletion was confirmed in $25 \%(63 / 252)$ and $24.97 \%$ $(180 / 721)$ of cases, respectively. Figure $2 \mathrm{~b}$ and c summarize the findings. A random-effect model and a fixed-effect model was chosen for meta-analysis as significant heterogeneity and no significant heterogeneity was observed, respectively $\left(\mathrm{I}^{2}=58 \%, P=0.09 ; \mathrm{I}^{2}=0 \%, P\right.$ $=0.76$ ). No statistically significant differences were found between tumors with and without GGO in patients with NSCLC having inherited these two mutation subtypes $(\mathrm{OR}=0.93,95 \% \mathrm{CI}=0.46-1.89, P=0.84 ; \mathrm{OR}=0.90,95 \%$ $\mathrm{CI}=0.63-1.28, P=0.54$, respectively).

\section{Non-solid GGO, part-solid GGO, solid tumor and EGFR mutation}

Five available articles were included for investigation of the relationship between non-solid and part-solid GGOs and EGFR mutation status. Out of a total of 64 tumors with non-solid GGOs and 162 part-solid GGOs, EGFR mutations were detected in $45.31 \%$ (29/64) and $61.73 \%(100 / 162)$ of cases, respectively. Figure 3a summarizes the findings. A fixed-effects model was used for meta-analysis as no significant heterogeneity was observed $\left(\mathrm{I}^{2}=6 \%, P=0.37\right)$. The EGFR mutation rate was significantly higher in tumors with part-solid GGOs compared with pure ones (pooled OR $=0.49$, 95\% CI $=0.25-0.96, P=0.04)$.

Four studies were available to study the relationship between non-solid GGOs and solid tumors or partsolid GGOs and solid tumors and the EGFR mutation status. A total of 50 non-solid GGOs, 151 part-solid GGOs and 249 solid tumors were found to have EGFR mutations in 48\% (24/50), 56.29\% (85/151), and $43.37 \%(108 / 249)$ of cases, respectively. Figure 3b and c summarize the findings. No statistically significant differences were observed between non-solid and solid tumors or part-solid and solid tumors and the EGFR mutation status, respectively $\left(\mathrm{I}^{2}=78 \%\right.$, pooled $\mathrm{OR}=$ 1.10, 95\% CI $=0.14-8.55, \quad P=0.93 ; \mathrm{I}^{2}=86 \%$, pooled $\mathrm{OR}=1.98,95 \% \mathrm{CI}=0.55-7.09, P=0.30$, respectively).

\section{Proportion of GGO and EGFR mutation}

Four studies investigated the relationship between tumors with a proportion of GGO less than or no less than $50 \%$ and EGFR mutation. Of a total of 264 tumors in the former group and 114 in the latter, EGFR mutations were detected in 50.38\% (133/264) and 26.32\% (30/114) of cases, respectively. Figure $3 \mathrm{~d}$ summarizes the findings. 


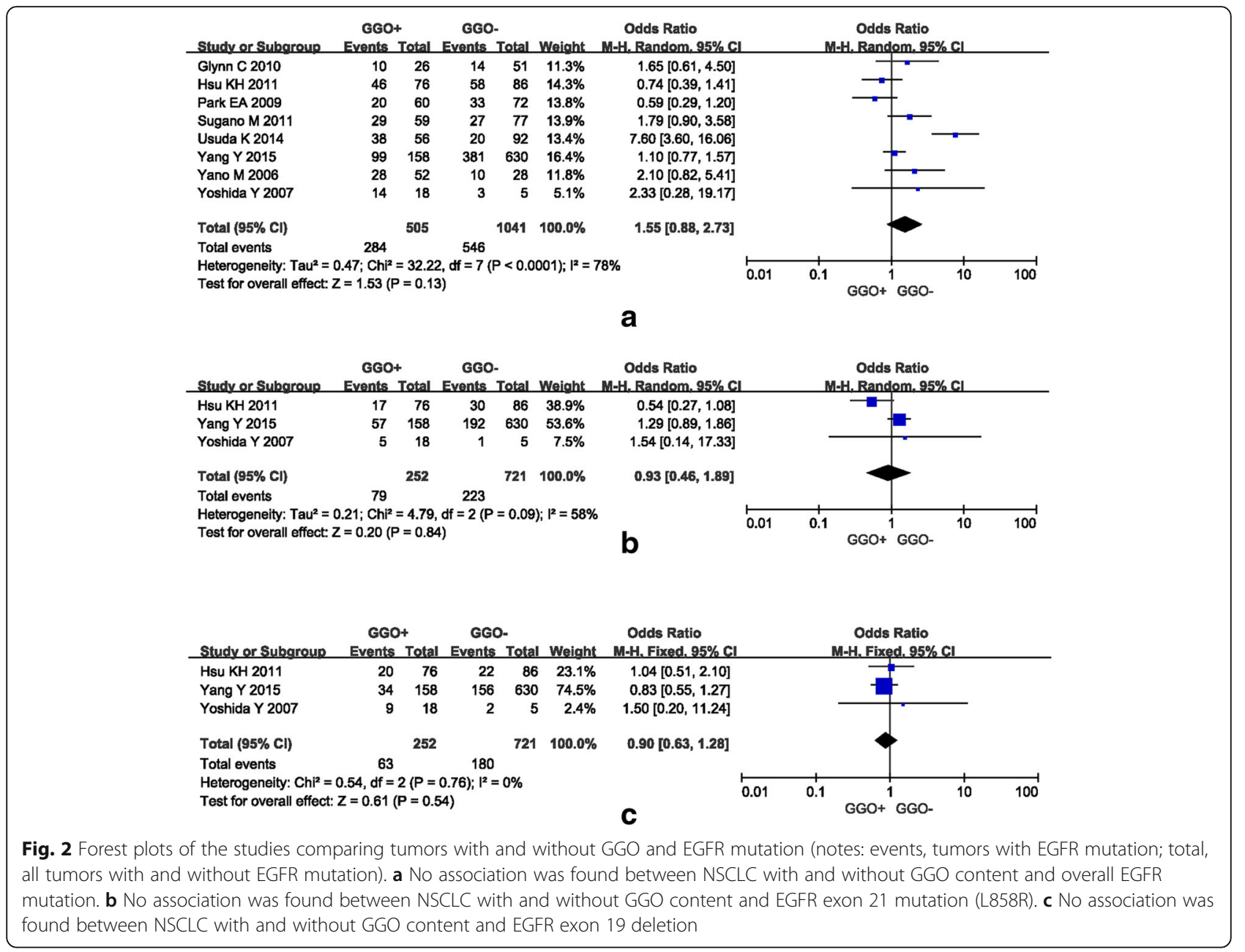

A random-effects model was utilized for meta-analysis due to significant heterogeneity $\left(\mathrm{I}^{2}=94 \%, \mathrm{P}<0.00001\right)$. No statistically significant difference was found between these two groups and EGFR mutation (pooled $\mathrm{OR}=$ 4.13, $95 \% \mathrm{CI}=0.31-54.28, P=0.28)$.

\section{Other morphological features and EGFR mutation Tumor size and EGFR mutation}

Five studies investigated the relationship between tumor size and EGFR mutation status: a total of 299 NSCLCs with average size ranging from 1.92 to $2.7 \mathrm{~cm}$ with inherited EGFR mutation and 433 tumors measuring between 1.43 and $3.74 \mathrm{~cm}$ without EGFR mutation were pooled into the meta-analysis. Figure 4a summarizes the findings. A random-effects model was adopted because of significant heterogeneity $\left(\mathrm{I}^{2}=92 \%, \mathrm{P}<0.00001\right)$. No statistically significant difference was demonstrated between NSCLCs with or without EGFR mutation and tumor size (pooled $\mathrm{WMD}=-0.04,95 \% \mathrm{CI}=-0.73-0.66, P=0.91)$.

\section{Tumor cavitation and EGFR mutation}

Four studies investigated on the relationship between tumor cavitation and EGFR mutation status. A total of 23 out of 211 NSCLCs had cavitation with EGFR mutation (10.90\%) compared to 33 out of 317 NSCLCs without EGFR mutation (10.41\%). Figure $4 \mathrm{~b}$ presents the findings. A fixed-effects model was adopted as no significant heterogeneity was noted $\left(\mathrm{I}^{2}=0 \%, P=0.51\right)$. No significant difference was observed between tumors with or without cavitation and EGFR mutation (pooled OR = $1.15,95 \% \mathrm{CI}=0.60-2.19, P=0.67)$.

\section{Other CT features and EGFR mutation}

In regard to relationship between tumors with or without air-bronchogram, lobulation, and spiculation and EGFR mutation, Fig. 4c, d, and e summarize the findings, respectively. The meta-analyses showed no significant differences between tumors with or without these CT features and EGFR mutation $(P=0.12,0.45$, and 0.36 , respectively). 


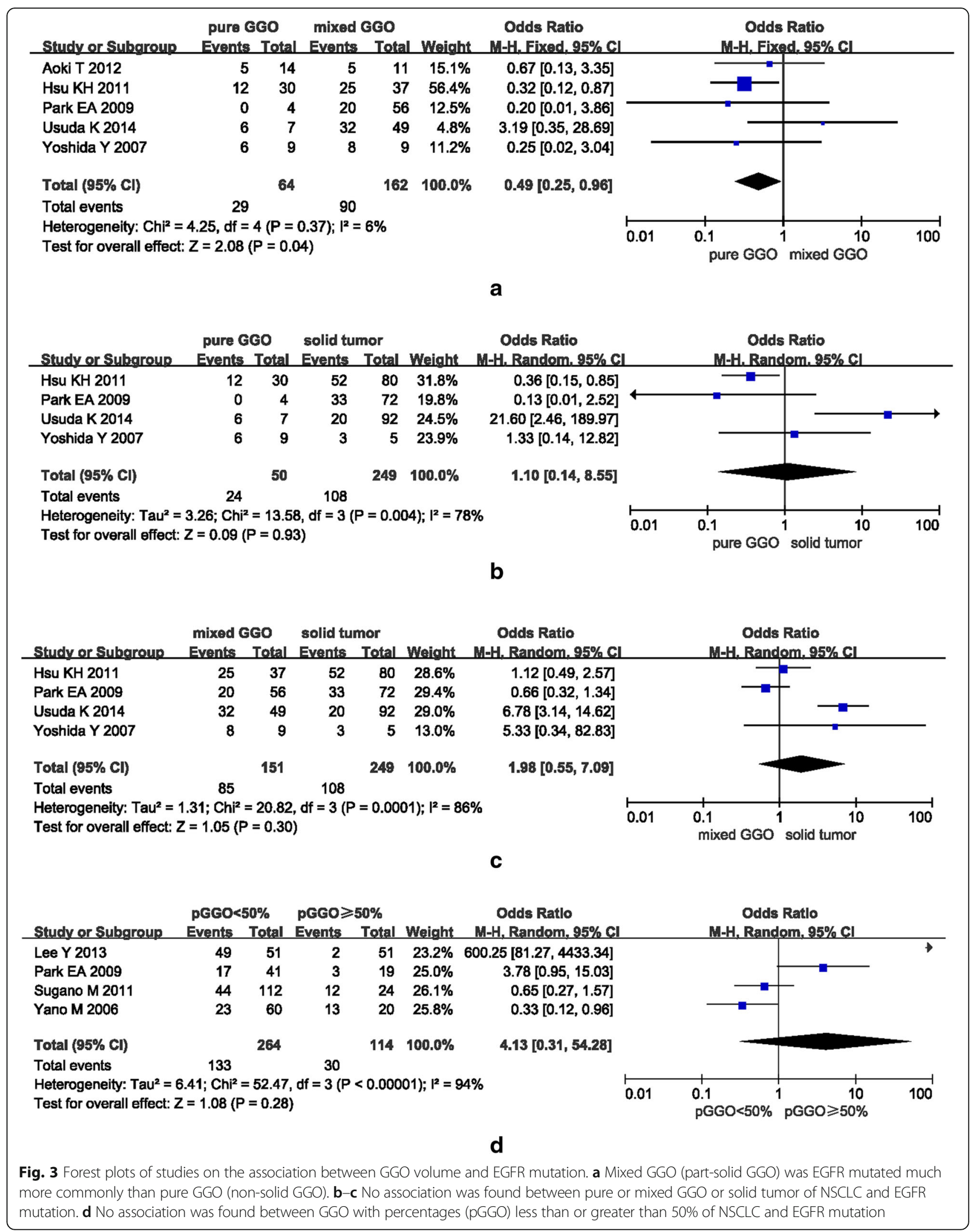




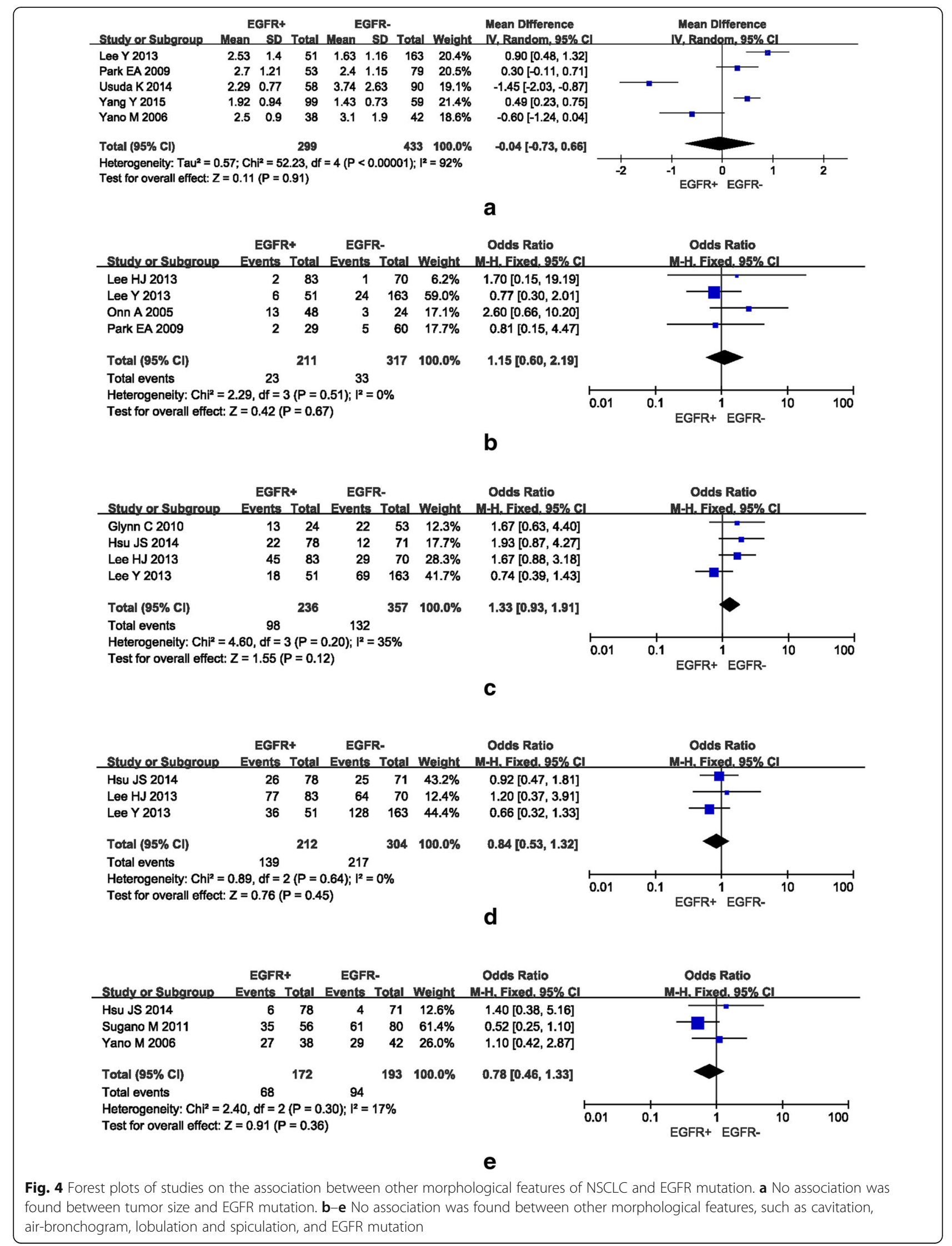


No publication bias was noted in this meta-analysis (Egger's test, $P>0.05$ for all). The summarized results are shown in Table 2.

\section{Discussion}

This meta-analysis investigated the radiogenomics of NSCLCs inherited with EGFR mutation and the results revealed that NSCLCs with part-solid GGOs rather than non-solid ones tended to be EGFR mutated. Other CT features such as tumor size, cavitation, air-bronchogram, lobulation and spiculation were not correlated with EGFR mutation.

The determination of the EGFR mutation status is crucial for the personalized treatment in patients with lung cancer and provides a molecular target that may be treated using anti-EGFR drugs. However, the successful detection of EGFR mutation is limited due to either insufficient pathological tissue collected by invasive aspiration or precluded due to the high cost of molecular examination. Therefore, a noninvasive and cost-effective modality is preferred. Based upon the reports that GGOs manifested on thin-section CT have been found to be associated with certain histopathological types, such as atypical adenomatous hyperplasia (AAH), adenocarcinoma in situ (AIS, previously known as bronchioloalveolar carcinoma $(\mathrm{BAC})$ ), and minimally invasive adenocarcinoma (MIA, previously known as adenocarcinoma with a predominant BAC component (ABAC)) [22], and that EGFR mutation is frequently detected in these pathological subtypes, we sought to study whether the detection of GGO on CT correlates with EGFR mutation.

Although many retrospective studies have reported that GGO was more frequent in tumors with EGFR

Table 2 Summary of Egger's tests

\begin{tabular}{|c|c|c|}
\hline \multirow[t]{2}{*}{ Meta-analysis } & \multicolumn{2}{|c|}{ Egger's test } \\
\hline & $t$ value & $P$ value \\
\hline $\mathrm{GGO}(+/-) \sim \mathrm{EGFR}$ & -0.11 & 0.915 \\
\hline $\mathrm{GGO}(\geq /<50 \%) \sim \mathrm{EGFR}$ & 2.05 & 0.177 \\
\hline GGO $($ pure/mixed) $\sim$ EGFR & 0.71 & 0.551 \\
\hline $\mathrm{GGO}($ mixed/-) $\sim \mathrm{EGFR}$ & 0.22 & 0.847 \\
\hline GGO (pure/-) $\sim$ EGFR & 1.03 & 0.490 \\
\hline $\mathrm{GGO}(+/-) \sim \operatorname{exon} 21$ & -2.00 & 0.295 \\
\hline $\mathrm{GGO}(+/-) \sim \operatorname{exon} 19$ & 7.70 & 0.082 \\
\hline Size $\sim$ EGFR & -1.63 & 0.201 \\
\hline Cavitation (+/-) EGFR & -1.89 & 0.199 \\
\hline Air-bronchogram $(+/-) \sim$ EGFR & -0.31 & 0.787 \\
\hline Lobulation $(+/-) \sim$ EGFR & 0.50 & 0.703 \\
\hline Spiculation (+/-) EGFR & -1.89 & 0.310 \\
\hline
\end{tabular}

Notes: GGO ground glass opacity, EGFR epidermal growth factor receptor; + Indicating with; - indicating without; $\geq /<50 \%$ indicating $\%$ GGO volume greater than/equal to or less than $50 \%$ mutation [28, 37, 39-41], this meta-analysis revealed that NSCLC with or without GGO did not differ in terms of their EGFR mutation status. A possible explanation may be the heterogeneity of the study population related to some demographic or clinical features. Just as Sugano $\mathrm{M}$ et al. [29] reported that there was no significant association between GGO and EGFR mutation, but that the EGFR mutation occurred more frequently in male patients with GGO, this gender difference may be accounted for by cross-talk between EGFR and estrogen receptors [42]. Such subgroup analysis was not performed in this meta-analysis because of the lack of qualified studies available. Additionally, the two most common activating mutation subtypes, short in-frame deletions of exon 19, and point mutation (CTG to CGG) in exon 21 at nucleotide 2573 (L858R) [43], did not differ in NSCLCs with or without GGO neither, although Hsu et al. [36] found that a typical EGFR mutation, especially L858R, was more frequent in tumors (stage I) with invasive solid pattern and significantly less in tumors (stage I) with non-solid GGO. Again, the heterogeneity in different tumor stages or histological subtypes may have played a role in this aspect.

Regarding the proportion of GGO, this meta-analysis demonstrated that NSCLCs with part-solid GGO rather than the non-solid GGO tended to be EGFR mutated, which is consistent with results of several other recent studies indicating that mixed GGOs (part-solid GGOs), especially those with a lower percentage of GGO had a higher rate of EGFR TK domain mutation [27, 36, 41, 44]. A possible mechanism might be that EGFR, an oncogene, played an important role in carcinogenesis and tumor progression via activation of the RAS/RAF/ MEK/MAPK and the PI3K/AKT/mTOR pathways if mutated $[45,46]$ and that the incidence of EGFR mutation may be up-regulated by enhanced activation of certain pathways during the progression of tumors from a non-solid GGO to a part-solid pattern.

In regard to the correlation between tumor size and EGFR mutation status, a tendency was found that the bigger the tumor was, the more frequent the EGFR mutated $[26,28,38,40]$, although the present meta-analysis did not show a statistically significant difference. This was probably due to other potential confounders that may have interacted with the tumor size. As Yano $M$ et al. [28] noted, GGO was more frequently observed in EGFR mutation, and although a significant difference was not reached individually, there was a significant difference if taking both tumor size and proportion of GGO into consideration. Other CT features such as cavitation, air-bronchogram, lobulation and spiculation were also examined in this meta-analysis; however, no correlation with EGFR mutation was found. With more accumulated data in the future, a meta-regression may 
be utilized to further investigate the underlying interactive features.

There are some limitations in this meta-analysis. First, the sample size in a few subgroups was small, thus the test effect may be lower and a false negative finding would be introduced. Second, as there were no randomized controlled trials (RCT) available and the majority of studies were retrospective, this may have introduced a selection bias that could influence the final overall effect. Third, CT scanning parameters and EGFR mutation detection methods were heterogeneous across the retrieved studies, and this may have increased the risk of interstudy heterogeneity. Lastly, meta-regression analysis was not performed due to the small number of subgroups.

\section{Conclusions}

In conclusion, this meta-analysis demonstrated that EGFR mutation tended to be inherited in NSCLCs with part-solid GGOs compared tumors with non-solid GGO pattern. There was no correlation between EGFR mutation and other CT features such as tumor size, cavitation, air-bronchogram, lobulation and spiculation. As most eligible studies were retrospectively performed and had a relatively small sample size, future prospective studies with a larger sample size are warranted for further clarification of the relationship between molecular markers and CT morphological characteristics, thus providing supporting evidence for potential molecular targets that may be treated using molecular drugs.

\section{Additional file}

Additional file 1: PRISMA-checklist. (DOC $67 \mathrm{~kb}$ )

\begin{abstract}
Abbreviations
AAH: Atypical adenomatous hyperplasia; ABAC: Adenocarcinoma with a predominant BAC component; AIS: Adenocarcinoma in situ; ALK: Anaplastic lymphoma kinase; BAC: Bronchioloalveolar carcinoma; CT: Computed tomography; EGFR: Epidermal growth factor receptor; EGFR-TKI: EGFR tyrosine kinase inhibitor; FISH: Fluorescence in situ hybridization; GGO: Ground-glass opacity; HER2: Human epidermal growth factor receptor 2; $I^{2}$ : Inconsistency index; IHC: Immunohistochemistry; KRAS: Kirsten rat sarcoma viral oncogene homolog; MIA: Minimally invasive adenocarcinoma; NGS: Next generation sequencing; NSCLC: Non-small cell lung cancer; PCR: Polymerase chain reaction; PFS: Progression-free survival; PRISMA: Preferred Reporting Items for Systematic Reviews and Meta-analyses; RCT: Randomized controlled trials
\end{abstract}

\section{Acknowledgments}

We sincerely thank Dr. Dan Xiong and Dr. Jianghua Zheng for their help in statistical analysis and editors from American Journal Experts for language editing.

\section{Funding}

This work was supported by the National Natural Science Foundation of China [grant number 81301223].

\section{Authors' contributions}

ZC participated in the design of the study, collected the data, performed the statistical analysis and drafted the manuscript. FS participated in the design of the study, analyzed the data, performed the statistical analysis and drafted the manuscript. ZZ participated in the design of the study and assisted with manuscript preparation. YY participated in the design of the study and assisted with manuscript preparation. YS assisted with manuscript preparation. All authors read and approved the final manuscript.

\section{Competing interests}

The authors declare that they have no competing interest.

\section{Consent for publication}

Not applicable.

\section{Ethics approval and consent to participate}

All studies included in this meta-analysis had been approved by their institutional review boards.

\section{Author details}

${ }^{1}$ Department of Radiology, Shanghai Public Health Clinical Center, Fudan University, NO.2901 Caolang Road, Jinshan, Shanghai 201508, China.

${ }^{2}$ Department of Radiology, Qingpu branch of Zhongshan Hospital, Fudan University, Shanghai 201700, China. ${ }^{3}$ Department of Medical Imaging, Sunnybrook Health Sciences Center, University of Toronto, Toronto, ON M4N 3M5, Canada.

Received: 23 May 2016 Accepted: 23 December 2016

Published online: 10 January 2017

\section{References}

1. Torre LA, Bray F, Siegel RL, Ferlay J, Lortet-Tieulent J, Jemal A. Global cancer statistics, 2012. CA Cancer J Clin. 2015;65(2):87-108.

2. Siegel RL, Miller KD, Jemal A. Cancer statistics, 2015. CA Cancer J Clin. 2015:65(1):5-29.

3. Chen W, Zheng R, Baade PD, Zhang S, Zeng H, Bray F, Jemal A, Yu XQ, He J. Cancer statistics in China, 2015. CA Cancer J Clin. 2016;66(2):115-32.

4. Yang L, Parkin DM, Ferlay J, Li L, Chen Y. Estimates of cancer incidence in China for 2000 and projections for 2005. Cancer Epidemiol Biomarkers Prev. 2005;14(1):243-50

5. Begum S, Brait M, Dasgupta S, Ostrow KL, Zahurak M, Carvalho AL, Califano JA, Goodman SN, Westra WH, Hoque MO, et al. An epigenetic marker panel for detection of lung cancer using cell-free serum DNA. Clin Cancer Res. 2011;17(13):4494-503.

6. Singhal S, Vachani A, Antin-Ozerkis D, Kaiser LR, Albelda SM. Prognostic implications of cell cycle, apoptosis, and angiogenesis biomarkers in nonsmall cell lung cancer: a review. Clin Cancer Res. 2005;11(11):3974-86.

7. Wardwell NR, Massion PP. Novel strategies for the early detection and prevention of lung cancer. Semin Oncol. 2005;32(3):259-68.

8. Maemondo M, Inoue A, Kobayashi K, Sugawara S, Oizumi S, Isobe H, Gemma A, Harada M, Yoshizawa H, Kinoshita I, et al. Gefitinib or chemotherapy for non-small-cell lung cancer with mutated EGFR. N Engl J Med. 2010;362(25):2380-8.

9. Paez JG, Janne PA, Lee JC, Tracy S, Greulich H, Gabriel S, Herman P, Kaye FJ, Lindeman N, Boggon TJ, et al. EGFR mutations in lung cancer: correlation with clinical response to gefitinib therapy. Science. 2004;304(5676):1497-500.

10. Solomon BJ, Mok T, Kim DW, Wu YL, Nakagawa K, Mekhail T, Felip E, Cappuzzo F, Paolini J, Usari T, et al. First-line crizotinib versus chemotherapy in ALK-positive lung cancer. N Engl J Med. 2014;371(23):2167-77.

11. Shaw AT, Kim DW, Mehra R, Tan DS, Felip E, Chow LQ, Camidge DR, Vansteenkiste J, Sharma S, De Pas T, et al. Ceritinib in ALK-rearranged nonsmall-cell lung cancer. N Engl J Med. 2014;370(13):1189-97.

12. Shaw AT, Ou SH, Bang YJ, Camidge DR, Solomon BJ, Salgia R, Riely GJ, Varella-Garcia M, Shapiro Gl, Costa DB, et al. Crizotinib in ROS1-rearranged non-small-cell lung cancer. N Engl J Med. 2014;371(21):1963-71.

13. Drilon A, Wang L, Hasanovic A, Suehara Y, Lipson D, Stephens P, Ross J, Miller V, Ginsberg M, Zakowski MF, et al. Response to Cabozantinib in patients with RET fusion-positive lung adenocarcinomas. Cancer Discov. 2013;3(6):630-5.

14. Gazdar AF. Personalized medicine and inhibition of EGFR signaling in lung cancer. N Engl J Med. 2009;361(10):1018-20. 
15. Nishino M, Hatabu H, Johnson BE, McLoud TC. State of the art: Response assessment in lung cancer in the era of genomic medicine. Radiology. 2014;271(1):6-27.

16. Suzuki M, Shigematsu $H$, lizasa T, Hiroshima K, Nakatani $Y$, Minna JD, Gazdar AF, Fujisawa T. Exclusive mutation in epidermal growth factor receptor gene, HER-2, and KRAS, and synchronous methylation of nonsmall cell lung cancer. Cancer. 2006;106(10):2200-7.

17. Mok TS, Wu YL, Thongprasert S, Yang CH, Chu DT, Saijo N, Sunpaweravong P, Han B, Margono B, Ichinose $Y$, et al. Gefitinib or carboplatin-paclitaxel in pulmonary adenocarcinoma. N Engl J Med. 2009;361(10):947-57.

18. Rosell R, Carcereny E, Gervais R, Vergnenegre A, Massuti B, Felip E, Palmero R, Garcia-Gomez R, Pallares C, Sanchez JM, et al. Erlotinib versus standard chemotherapy as first-line treatment for European patients with advanced EGFR mutation-positive non-small-cell lung cancer (EURTAC): a multicentre, open-label, randomised phase 3 trial. Lancet Oncol. 2012;13(3):239-46.

19. Sequist LV, Martins RG, Spigel D, Grunberg SM, Spira A, Janne PA, Joshi VA, McCollum D, Evans TL, Muzikansky A, et al. First-line gefitinib in patients with advanced non-small-cell lung cancer harboring somatic EGFR mutations. J Clin Oncol. 2008;26(15):2442-9.

20. Ellison G, Zhu G, Moulis A, Dearden S, Speake G, McCormack R. EGFR mutation testing in lung cancer: a review of available methods and their use for analysis of tumour tissue and cytology samples. J Clin Pathol. 2013;66(2):79-89.

21. Khoo C, Rogers TM, Fellowes A, Bell A, Fox S. Molecular methods for somatic mutation testing in lung adenocarcinoma: EGFR and beyond. Transl Lung Cancer Res. 2015;4(2):126-41.

22. Lee HY, Lee KS. Ground-glass opacity nodules: histopathology, imaging evaluation, and clinical implications. J Thorac Imaging. 2011;26(2):106-18.

23. Travis WD, Brambilla E, Noguchi M, Nicholson AG, Geisinger KR, Yatabe $Y$, Beer DG, Powell CA, Riely GJ, Van Schil PE, et al. International association for the study of lung cancer/american thoracic society/european respiratory society international multidisciplinary classification of lung adenocarcinoma. J Thorac Oncol. 2011;6(2):244-85.

24. Moher D, Liberati A, Tetzlaff J, Altman DG, Group P. Preferred reporting items for systematic reviews and meta-analyses: the PRISMA statement. Ann Intern Med. 2009;151(4):264-9. W264.

25. Aoki T, Nakata H, Watanabe H, Nakamura K, Kasai T, Hashimoto H, Yasumoto K, Kido M. Evolution of peripheral lung adenocarcinomas: $C T$ findings correlated with histology and tumor doubling time. AJR Am J Roentgenol. 2000;174(3):763-8.

26. Park EA, Lee HJ, Kim YT, Kang CH, Kang KW, Jeon YK, Goo JM, Lee CH, Park CM. EGFR gene copy number in adenocarcinoma of the lung by FISH analysis: investigation of significantly related factors on CT, FDG-PET, and histopathology. Lung Cancer. 2009;64(2):179-86.

27. Glynn C, Zakowski MF, Ginsberg MS. Are there imaging characteristics associated with epidermal growth factor receptor and KRAS mutations in patients with adenocarcinoma of the lung with bronchioloalveolar features? J Thorac Oncol. 2010;5(3):344-8.

28. Yano M, Sasaki H, Kobayashi Y, Yukiue H, Haneda H, Suzuki E, Endo K, Kawano O, Hara M, Fujii Y. Epidermal growth factor receptor gene mutation and computed tomographic findings in peripheral pulmonary adenocarcinoma. J Thorac Oncol. 2006;1(5):413-6.

29. Sugano M, Shimizu K, Nakano T, Kakegawa S, Miyamae Y, Kaira K, Araki T, Kamiyoshihara M, Kawashima O, Takeyoshi I. Correlation between computed tomography findings and epidermal growth factor receptor and KRAS gene mutations in patients with pulmonary adenocarcinoma. Oncol Rep. 2011;26(5):1205-11.

30. Onn A, Choe DH, Herbst RS, Correa AM, Munden RF, Truong MT, Vaporciyan AA, Isobe T, Gilcrease MZ, Marom EM. Tumor cavitation in stage I non-small cell lung cancer: epidermal growth factor receptor expression and prediction of poor outcome. Radiology. 2005;237(1):342-7.

31. Hsu JS, Huang MS, Chen CY, Liu GC, Liu TC, Chong IW, Chou SH, Yang CJ. Correlation between EGFR mutation status and computed tomography features in patients with advanced pulmonary adenocarcinoma. J Thorac Imaging. 2014;29(6):357-63.

32. Hansell DM, Bankier AA, MacMahon H, McLoud TC, Muller NL, Remy J. Fleischner Society: glossary of terms for thoracic imaging. Radiology. 2008;246(3):697-722.

33. Sweeting MJ, Sutton AJ, Lambert PC. What to add to nothing? Use and avoidance of continuity corrections in meta-analysis of sparse data. Stat Med. 2004;23(9):1351-75.

34. Jackson D, White IR, Riley RD. Quantifying the impact of between-study heterogeneity in multivariate meta-analyses. Stat Med. 2012;31(29):3805-20.
35. Aoki T, Hanamiya M, Uramoto H, Hisaoka M, Yamashita $Y$, Korogi Y. Adenocarcinomas with predominant ground-glass opacity: correlation of morphology and molecular biomarkers. Radiology. 2012;264(2):590-6.

36. Hsu KH, Chen KC, Yang TY, Yeh YC, Chou TY, Chen HY, Tsai CR, Chen CY, Hsu CP, Hsia JY, et al. Epidermal growth factor receptor mutation status in stage I lung adenocarcinoma with different image patterns. J Thorac Oncol. 2011;6(6):1066-72.

37. Lee HJ, Kim YT, Kang CH, Zhao B, Tan Y, Schwartz LH, Persigehl T, Jeon YK Chung $\mathrm{DH}$. Epidermal growth factor receptor mutation in lung adenocarcinomas: relationship with $\mathrm{CT}$ characteristics and histologic subtypes. Radiology. 2013;268(1):254-64.

38. Lee Y, Lee HJ, Kim YT, Kang CH, Goo JM, Park CM, Paeng JC, Chung DH, Jeon YK. Imaging characteristics of stage I non-small cell lung cancer on $\mathrm{CT}$ and FDG-PET: relationship with epidermal growth factor receptor protein expression status and survival. Korean J Radiol. 2013;14(2):375-83.

39. Usuda K, Sagawa M, Motono N, Ueno M, Tanaka M, Machida Y, Matoba M, Taniguchi M, Tonami H, Ueda $Y$, et al. Relationships between EGFR mutation status of lung cancer and preoperative factors - are they predictive? Asian Pac J Cancer Prev. 2014;15(2):657-62.

40. Yang Y, Yang Y, Zhou X, Song X, Liu M, He W, Wang H, Wu C, Fei K, Jiang G. EGFR L858R mutation is associated with lung adenocarcinoma patients with dominant ground-glass opacity. Lung Cancer. 2015;87(3):272-7.

41. Yoshida Y, Kokubu A, Suzuki K, Kuribayashi H, Tsuta K, Matsuno Y, Kusumoto M, Kanai Y, Asamura H, Hirohashi S, et al. Molecular markers and changes of computed tomography appearance in lung adenocarcinoma with groundglass opacity. Jpn J Clin Oncol. 2007;37(12):907-12.

42. Marquez-Garban DC, Chen HW, Fishbein MC, Goodglick L, Pietras RJ. Estrogen receptor signaling pathways in human non-small cell lung cancer. Steroids. 2007;72(2):135-43.

43. Ladanyi M, Pao W. Lung adenocarcinoma: guiding EGFR-targeted therapy and beyond. Mod Pathol. 2008;21 Suppl 2:S16-22.

44. Chung JH, Choe G, Jheon S, Sung SW, Kim TJ, Lee KW, Lee JH, Lee CT. Epidermal growth factor receptor mutation and pathologic-radiologic correlation between multiple lung nodules with ground-glass opacity differentiates multicentric origin from intrapulmonary spread. J Thorac Oncol. 2009;4(12):1490-5.

45. Doroshow JH. Targeting EGFR in non-small-cell lung cancer. N Engl J Med. 2005;353(2):200-2

46. Salomon DS, Brandt R, Ciardiello F, Normanno N. Epidermal growth factorrelated peptides and their receptors in human malignancies. Crit Rev Oncol Hematol. 1995;19(3):183-232.

\section{Submit your next manuscript to BioMed Central and we will help you at every step:}

- We accept pre-submission inquiries

- Our selector tool helps you to find the most relevant journal

- We provide round the clock customer support

- Convenient online submission

- Thorough peer review

- Inclusion in PubMed and all major indexing services

- Maximum visibility for your research

Submit your manuscript at www.biomedcentral.com/submit
) Biomed Central 